\title{
The Precise Sequence of FGF Receptor Autophosphorylation Is Kinetically Driven and Is Disrupted by Oncogenic Mutations
}

\author{
Erin D. Lew ${ }^{*}$, Cristina M. Furdui ${ }^{\dagger}$, Karen S. Anderson, and Joseph Schlessinger ${ }^{\ddagger}$ \\ Department of Pharmacology, Yale University School of Medicine 333 Cedar Street, New Haven, \\ CT 06520, USA
}

\begin{abstract}
Autophosphorylation of the tyrosine kinase domain of fibroblast growth factor receptor 1 (FGFR1) is mediated by a sequential and precisely ordered three-stage autophosphorylation reaction. Firststage autophosphorylation of an activation loop tyrosine leads to 50- to 100-fold stimulation of kinase activity and is followed by second-stage phosphorylation of three additional tyrosine residues, which are binding sites for signaling molecules. Finally, third-stage phosphorylation of a second activation loop tyrosine leads to an additional 10-fold stimulation of FGFR1 catalytic activity. In this report, we show that sequential autophosphorylation of five tyrosines in the FGFR1 kinase domain is under kinetic control, mediated by both the amino acid sequence surrounding the tyrosines and their locations within the kinase structure and, moreover, that phosphoryl transfer is the rate-limiting step. Furthermore, the strict order of autophosphorylation is disrupted by a glioblastoma-derived, oncogenic FGFR1 point mutation in the kinase domain. We propose that disrupted stepwise activation of tyrosine autophosphorylation caused by oncogenic and other activating FGFR mutations may lead to aberrant activation of and assembly of signaling molecules by the activated receptor.
\end{abstract}

\section{INTRODUCTION}

Autophosphorylation of receptor tyrosine kinases (RTKs) relieves cis-autoinhibitory constraints that maintain the tyrosine kinase domain in an autoinhibited, low-activity state and generates sites for the recruitment of signaling molecules that bind to tyrosine phosphorylation sites through their Src homology 2 (SH2) or phosphotyrosine binding (PTB) domains. Autophosphorylation of tyrosine residues in the tyrosine kinase domain of fibroblast growth factor receptor 1 (FGFR1) is mediated by an intermolecular (trans) process that occurs in a precise sequence (1). Tyrosine autophosphorylation appears to occur in three stages. The first stage involves phosphorylation of $\mathrm{Y}^{653}(2)$ in the activation loop of the catalytic core; this leads to a 50- to 100-fold stimulation of FGFR1's intrinsic tyrosine kinase activity.

Autophosphorylation of $\mathrm{Y}^{653}$ is followed by the ordered autophosphorylation of several key tyrosine residues within binding sites for the $\mathrm{SH} 2$ or PTB domains of signaling proteins that bind to and are phosphorylated by activated FGFR1. This second-stage autophosphorylation occurs on $\mathrm{Y}^{583}$, in the kinase insert region (a noncatalytic sequence within the kinase domain), followed by autophosphorylation of $Y^{463}$ in the juxtamembrane region, $\mathrm{Y}^{766}$ in the C-terminal tail, and $\mathrm{Y}^{585}$ in the kinase insert region (1). The third-stage autophosphorylation takes place on the second tyrosine in the activation loop $\left(\mathrm{Y}^{654}\right)$, resulting in an additional 10 -fold increase in the intrinsic tyrosine kinase activity of FGFR1. We have proposed that the role of the third

\footnotetext{
*Present address: Molecular Neurobiology Laboratory, The Salk Institute, 10010 N. Torrey Pines Road, La Jolla, CA 92037, USA.

$\dagger$ Present address: Department of Internal Medicine, Section on Molecular Medicine, Wake Forest University School of Medicine, Winston-Salem, NC 27157, USA.

\#To whom correspondence should be addressed. joseph.schlessinger@yale.edu
} 
stage of autophosphorylation is to enable the efficient tyrosine phosphorylation of substrate proteins that are physically bound to the receptor molecule by a maximally activated FGFR1 (1).

Ordered autophosphorylation of tyrosine residues in the activation loops of several RTKs, including the insulin receptor, the insulin-like growth factor 1 (IGF-1) receptor, Tie2, and muscle-specific kinase (MuSK) has also been described (3-7). However, the mechanism of this ordered phosphorylation - and even whether it serves an in vivo function-remains unclear. Most research has focused on finding substrates and substrate recognition motifs for molecules downstream of the protein tyrosine kinases (PTKs) rather than on examining the tyrosine autophosphorylation sites themselves as substrates. Researchers have used high-throughput methods such as mass spectrometry (8-11), protein microarray chips $(12,13)$, and degenerate peptide libraries (14-16) together with computational algorithms (17) to define optimal linear phosphorylation motifs for specific PTKs. In addition, the crystal structures of activated insulin receptor kinase (IRK) in complex with a peptide substrate derived from insulin receptor substrate-1 (IRS-1) and that of Abl kinase in complex with a bisubstrate analog have provided insight into the structural basis for the substrate specificity of RTKs (18-20). In scanning peptide libraries, RTKs generally select for acidic residues at positions immediately $\mathrm{N}$-terminal to the tyrosine phosphorylation site, and in the IRK structure, an aspartic acid at the P-1 position of the peptide substrate forms a water-mediated hydrogen bond to $\mathrm{K}^{1085}$ of the kinase (19).

However, this residue is not highly conserved among RTKs, and scanning data for the optimal peptide substrate for Abl kinase has shown that these acidic residues may not be entirely necessary or sufficient for substrate recognition. In addition, large hydrophobic residues are selected by scanning peptide libraries at the $\mathrm{P}+1$ and $\mathrm{P}+3$ positions of the substrate. These two hydrophobic residues, methionines in the case of IRK, were accommodated by two adjacent hydrophobic pockets on the surface of the C-terminal lobe of the kinase. Thus, although peptide libraries and structural studies have yielded insight into RTK substrate recognition, they have not been able to fully explain the complex interactions or specificity between the kinase and the substrate molecules. For example, the recognition of $\mathrm{Y}^{527}$ on Src by the C-terminal Src kinase Csk occurs in the context of the intact molecule and is not recapitulated by peptide mimetics alone (21).

To begin to understand the molecular mechanism underlying the order of FGFR1 autophosphorylation, we analyzed each tyrosine as a discrete substrate in the context of the intact FGFR1 kinase domain and asked if ordered autophosphorylation is kinetically controlled or mediated by some other regulatory mechanism (such as differential substrate affinity). Here, we show that sequential autophosphorylation of the five tyrosines in the FGFR1 catalytic core is under kinetic control and, further, that phosphoryl transfer is the rate-limiting step. In addition, we show that a mutation in the tyrosine kinase core of FGFR1 found in human glioblastoma alters the discrete order of tyrosine autophosphorylation, leading to more heterogeneous phosphorylation states. Moreover, expression of intact FGFR1 harboring this glioblastoma mutation in Rat-1 cells led to a transformed cellular phenotype. Taken together, these experiments show that ordered FGFR 1 autophosphorylation is precisely controlled by structural elements within the kinase domain, suggesting not only a universal mechanism for RTK autophosphorylation, but also that disruption of ordered autophosphorylation may contribute to the pathology observed in various RTK-mediated diseases.

\section{RESULTS}

To begin to dissect the mechanism of FGFR1 ordered autophosphorylation, we compared the primary structures of the FGFR1 tyrosine phosphorylation sites to the sequence of the optimal FGFR1 peptide substrate identified by screening random substrate peptide libraries $\left(\mathrm{NH}_{2}-\right.$ XEEEYFFLF-COOH) (22) (Fig. 1A). Degenerate peptide library scanning has shown that 
FGFR and other RTKs prefer peptide substrates with a string of acidic residues at positions $\mathrm{N}$ terminal to the tyrosine phosphorylation site and large hydrophobic residues at the $\mathrm{Y}+1$ and $\mathrm{Y}+3$ positions (22). However, aside from the single acidic residue at the $\mathrm{Y}-1$ position of the first three tyrosines phosphorylated $\left(\mathrm{Y}^{653}, \mathrm{Y}^{583}\right.$, and $\left.\mathrm{Y}^{463}\right)$, the remaining sequences surrounding the phosphorylated tyrosine sites diverged from each other and from that of the optimal substrate, suggesting that the primary structure alone could not account for the observed order of autophosphorylation.

We previously determined the order of autophosphorylation with the use of the tyrosine kinase domain of FGFR1 (1). The sequential order of phosphorylation may reflect varying degrees of accessibility of the individual tyrosine sites within the three-dimensional structure of the FGFR1 kinase domain. The location of the tyrosine autophosphorylation sites within different regions of the FGFR1 kinase domain tertiary structure would impose structural constraints for the incorporation of the tyrosine into the catalytic site. To examine each tyrosine as an individual substrate in the context of the intact kinase structure, we engineered FGFR1 kinase domain constructs to contain only a single tyrosine phosphorylation site, whereas the other four autophosphorylation sites were mutated to phenylalanine (Fig. 1B). Phosphorylation of $\mathrm{Y}^{730}$ occurs in low stoichiometry in vivo, presumably because it resides at the end of an $\alpha$ helix. In this system, phosphorylation of $Y^{730}$ was not observed and this residue was left intact. $\mathrm{D}^{623}$ is a highly conserved amino acid in the catalytic core required for catalysis that serves as the general base catalyst to abstract the hydroxyl proton from the substrate (23-26). Because the FGFR1 kinase domain undergoes autophosphorylation, an additional point mutation, D623A, was introduced to make the FGFR1 constructs that served as substrates catalytically inactive (called $\mathrm{Y}^{\mathrm{xxx}} \mathrm{KD}$, where $\mathrm{Y}^{\mathrm{xxx}}$ is the residue that can be phosphorylated and $\mathrm{KD}$ means kinase dead). A subsequent kinase assay confirmed that the constructs were indeed kinase dead (Fig. 1E), and their similar migration patterns by native gel electrophoresis suggest that mutation of the tyrosines does not cause a major conformational change in the structure (Fig. 1D).

To phosphorylate the kinase-dead substrates, we generated two kinase-active FGFR1 mutants (Fig. 1C) phosphorylated at either $\mathrm{Y}^{653}$ only $\left(\mathrm{Y}^{653}-1 \mathrm{P}\right)$ or bis-phosphorylated on $\mathrm{Y}^{653}$ and $\mathrm{Y}^{654}$ (FGFR1-3F-2P), both unable to undergo further phosphorylation as verified by an in vitro kinase assay (Fig. 1F). As previously noted, phosphorylation of $\mathrm{Y}^{653}$ increases FGFR1 catalytic activity 50- to 100-fold, and subsequent phosphorylation on $\mathrm{Y}^{654}$ increases its catalytic activity an additional 10-fold (1). Furthermore, under conditions in which wild-type or mutant FGFR1 are overexpressed, $\mathrm{Y}^{463}, \mathrm{Y}^{583}, \mathrm{Y}^{585}$, and $\mathrm{Y}^{730}$ are dispensable for tyrosine phosphorylation of Shc, the mitogen-activated protein kinase (MAPK) response, and stimulation of FGFR1mediated cell proliferation and differentiation (27). The $\mathrm{Y}^{653}-1 \mathrm{P}$ and FGFR1-3F-2P FGFR1 kinase domain mutants were autophosphorylated upon addition of adenosine 5 '-triphosphate (ATP) and $\mathrm{MgCl}_{2}$, and the differentially phosphorylated constructs were purified by anionexchange chromatography. The purity and position of the phosphate group was verified by native gel electrophoresis and mass spectrometry (Fig. 1F). Subsequent experiments were carried out with the fully activated form due to the faster reaction kinetics.

We next sought to establish if the observed order of FGFR1 autophosphorylation is under kinetic control. Autophosphorylation experiments used to determine the in vitro order were carried out at saturating concentrations of substrate $(35 \mu \mathrm{M})(1)$, where binding affinity of the substrate to the enzyme is not rate limiting and the observed rate $\left(k_{\mathrm{obs}}\right)$ reflects the rate of autophosphorylation. We similarly performed a kinase assay at three saturating concentrations of kinase-dead substrate $(10,15$, or $30 \mu \mathrm{M})$ with $0.1 \mu \mathrm{M}$ of the fully activated kinase (FGFR1-3F-2P) and followed the formation of the phosphorylated species by native gel electrophoresis over time (Fig. 2A). For each substrate, similar results were obtained at each substrate concentration, confirming that all experiments were done at saturation and indicating 
that the different rates observed were not due to substrate availability (Fig. 2B). Data for each substrate at the three concentrations were averaged, and the reaction rates for the formation of phosphorylated species were obtained by fitting the data to a single-exponential equation. The data were expressed as percentage of phosphorylated substrate, and the percentage for each time point was plotted as a function of time (Fig. 2, B and C). Subsequent mass spectrometry of the monophosphorylated kinase-dead substrates confirmed that the expected tyrosine site was phosphorylated (fig. S1). As illustrated in Fig. 2C, the rates of phosphorylation of $\mathrm{Y}^{653}$ and $\mathrm{Y}^{583}$ were the fastest and similar at 0.1080 and $0.1388 \mathrm{~min}^{-1}$, respectively. The phosphorylation of $\mathrm{Y}^{463}$ and of $\mathrm{Y}^{654}$ were intermediate at 0.0209 and $0.0151 \mathrm{~min}^{-1}$, respectively. Phosphorylation of $\mathrm{Y}^{585}$ was the slowest, with a rate of $0.0032 \mathrm{~min}^{-1}$, and phosphorylation of $\mathrm{Y}^{730}$, which has been previously shown to be phosphorylated at low stoichiometry, was not observed in this system. The observed rates, in general, are in good agreement with the order of autophosphorylation observed with the exception of $\mathrm{Y}^{654}$, which is phosphorylated at a rate much faster than would be expected.

The rate of phosphorylation can be rate-limited by ATP or adenosine 5'-diphosphate (ADP) binding and release; by the transfer of the phosphate group to the serine, threonine, or tyrosine moiety; or by product release (23). For the serine/threonine kinase adenosine $3^{\prime}, 5^{\prime}$ -

monophosphate (cAMP)-dependent protein kinase (PKA), phosphorylation of a peptide substrate was limited by product release controlled by the dissociation of ADP, whereas phosphotransfer was rapid (28). In the case of IRK, phosphotransfer is rate-limiting in the basal state, whereas in the activated kinase, phosphotransfer and product release are each partially rate-limiting (29). For the tyrosine kinase activity of ErbB2, product release is rate-limiting (30). Having found that the ordered autophosphorylation of FGFR1 is under kinetic control, we investigated the nature of the rate-limiting step that dictates the kinetics of tyrosine phosphorylation. The kinase used to phosphorylate the different substrates was identical, and saturating concentrations of ATP were used; therefore, ATP binding and the subsequent release of ADP from the fully activated kinase must be the same and cannot account for the differences observed in the rates of catalysis. To investigate whether transfer of the phosphate group or product release is rate-limiting, we performed rapid chemical quench experiments, in which the formation of phosphorylated substrate $\left(\mathrm{Y}^{463} \mathrm{KD}\right)$ was monitored over time. Catalysis that is limited by product release is characterized by biphasic reaction kinetics in which a rapid burst in the initial phase is followed by a linear steady-state phase of product release. A kinase assay was performed with 3-, 5-, or 10-fold excess substrate to kinase (Fig. 3A). The formation of phosphorylated $\mathrm{Y}^{463} \mathrm{KD}$ was monitored by the incorporation of ${ }^{32} \mathrm{P}$ and plotted as a function of time (Fig. 3B). $\mathrm{Y}^{463} \mathrm{KD}$ was chosen as a representative substrate for pre-steady-state kinetic experiments because of its average phosphorylation kinetics relative to the other substrates. Product formation did not appear to be biphasic, and data did not converge to a steady-state burst equation, but the data fit a single-exponential equation, suggesting that phosphotransfer rather than product release is the rate-limiting step.

Mapping studies have shown that $\mathrm{Y}^{654}$ is the fifth site phosphorylated; however, the rate of $\mathrm{Y}^{654}$ phosphorylation was consistent with its being the third or fourth best substrate. $\mathrm{Y}^{654}$ is adjacent to $\mathrm{Y}^{653}$, the first site phosphorylated, and we postulated that phosphorylation at $\mathrm{Y}^{653}$ decreases the rate of $\mathrm{Y}^{654}$ phosphorylation as a consequence of charge repulsion between two adjacent negatively charged phosphate groups. To address this possibility, we constructed a kinase-dead mutant containing both $\mathrm{Y}^{653}$ and $\mathrm{Y}^{654}$ with the other tyrosines mutated to phenylalanine (Fig. 3C). We purified the monophosphorylated species (pY ${ }^{653} / \mathrm{Y}^{654} \mathrm{KD}$ ) by anion-exchange chromatography and used mass spectrometry to verify that the sample was indeed homogeneously phosphorylated only at $\mathrm{Y}^{653}$. We next performed a kinase assay at two saturating concentrations of substrate $(15$ and $30 \mu \mathrm{M})$ by incubating $0.1 \mu \mathrm{M}$ FGFR1K-3F-2P with ATP and $\mathrm{MgCl}_{2}$ to a final concentration of 5 and $10 \mathrm{mM}$ at $25^{\circ} \mathrm{C}$, respectively (Fig. 3D). We quenched the reaction samples by addition of EDTA (final concentration $50 \mathrm{mM}$ ), and 
compared the rates of phosphorylation of $\mathrm{Y}^{654} \mathrm{KD}$ and $\mathrm{pY} \mathrm{Y}^{653} / \mathrm{Y}^{654} \mathrm{KD}$. The reaction rates for $\mathrm{Y}^{654} \mathrm{KD}$ and $\mathrm{pY}^{653} / \mathrm{Y}^{654} \mathrm{KD}$ phosphorylation were similar $(0.0209 \pm 0.001$ and $0.0271 \pm 0.002$ $\min ^{-1}$, respectively) (Fig. 3E), suggesting that under these conditions, prior phosphorylation at $Y^{653}$ does not slow subsequent phosphorylation at $Y^{654}$ and that additional factors affect the rate of $Y^{654}$ phosphorylation.

Based on the high-resolution crystal structure of FGFR1 kinase domain (31), the autophosphorylation sites are found in various regions of the kinase domain. $\mathrm{Y}^{463}$ is at the $\mathrm{N}$ terminus near the boundary of the juxtamembrane domain, $\mathrm{Y}^{583}$ and $\mathrm{Y}^{585}$ are in the flexible kinase insert, $\mathrm{Y}^{653}$ and $\mathrm{Y}^{654}$ are in the activation loop, and $\mathrm{Y}^{730}$ is at the end of the $\alpha \mathrm{H}$ helix. Two pairs of tyrosines are adjacent to one another, $\mathrm{Y}^{583} / \mathrm{Y}^{585}$ and $\mathrm{Y}^{653} / \mathrm{Y}^{654}$; however, they are not phosphorylated sequentially, suggesting that the location of the tyrosine moieties within the tertiary structure alone does not solely dictate the order of autophosphorylation observed.

As previously mentioned, one of the hallmarks of optimal peptide substrates for RTKs is a series of acidic residues at positions immediately $\mathrm{N}$-terminal to the tyrosine phosphorylation site. As noted, the first three sites phosphorylated (and also $\mathrm{Y}^{766}$ ) have an acidic residue at the Y - 1 position, which may enhance the recognition of particular tyrosines by the kinase, especially in the case of adjacent tyrosine autophosphorylation sites where structural constraints should play a lesser role. To determine if these acidic residues play a role in determining the order of autophosphorylation, kinase-dead mutants of $\mathrm{Y}^{654}$, in which the $\mathrm{Y}$ 1 residue was mutated to aspartic acid ( $\left.\mathrm{Y}^{654} \mathrm{KD} \_\Delta\right)$, and of $\mathrm{Y}^{585}$, in which the $\mathrm{Y}-1$ residues of $\mathrm{Y}^{583}$ and $\mathrm{Y}^{585}$ were swapped ( $\mathrm{Y}^{585} \mathrm{KD} \_\Delta$ ), were made (Fig. 3, $\mathrm{F}$ and $\mathrm{G}$ ). We next performed a kinase assay at saturating concentration of substrate $(30 \mu \mathrm{M})$ with $0.1 \mu \mathrm{M}$ of fully activated kinase and compared the rate of phosphorylation of $\mathrm{Y}^{654} \mathrm{KD}$ and $\mathrm{Y}^{654} \mathrm{KD} \_\Delta$ or $\mathrm{Y}^{585} \mathrm{KD}$ and $\mathrm{Y}^{585} \mathrm{KD} \_\Delta$, respectively. The rate of $\mathrm{Y}^{654} \mathrm{KD} \_\Delta$ phosphorylation was much faster than that of Y654KD phosphorylation and occurred at a rate comparable to that observed for $\mathrm{Y}^{653} \mathrm{KD}$, suggesting that the aspartic acid at the $\mathrm{Y}-1$ position plays a key role in the recognition of $\mathrm{Y}^{653}$ before that of $\mathrm{Y}^{654}$. On the other hand, although the rate of $\mathrm{Y}^{585} \mathrm{KD} \_\Delta$ phosphorylation was faster than that of $\mathrm{Y}^{585} \mathrm{KD}$ phosphorylation, its rate was slower than that observed for $\mathrm{Y}^{583} \mathrm{KD}$. Thus, both the amino acid sequence surrounding $\mathrm{Y}^{585}$ and the location of $\mathrm{Y}^{585}$ within the FGFR1 kinase tertiary structure appear to affect the recognition as substrate of the adjacent tyrosine residues in the kinase insert.

Having observed that the sequential order of FGFR1 autophosphorylation is dictated by both the amino acid sequence surrounding the tyrosine autophosphorylation site and the accessibility of each of the tyrosine moieties, we postulated that point mutations in the kinase domain responsible for FGFR1-mediated diseases may influence the local environment of the tyrosine and, thus, change the order of tyrosine autophosphorylation. Bidirectional dideoxy sequencing of 19 primary glioblastoma tumors has implicated two gain-of-function mutations in the FGFR1 kinase domain in human glioblastoma (32). Based on the structure of the FGFR1 kinase domain, one of these mutations, N546K, resides in the vicinity of the hinge region between the $\mathrm{N}$ and $\mathrm{C}$ lobes, and recent crystallographic evidence suggests that mutation of this residue (N549H in FGFR2) may affect the conformational dynamics of the tyrosine kinase domain by altering the flexibility of the hinge region to modulate the transition between the inactive and active states $(33,34)$ (Fig. 4B).

The N546K point mutation was introduced into the FGFR1 kinase domain and tyrosine autophosphorylation was analyzed by a combined approach of rapid chemical quench and native gel electrophoresis with densitometric analysis (Fig. 5). As with wild-type FGFR1 kinase, the reaction proceeds via a sequential mechanism with a discrete set of phosphoproteins formed over time. The relative abundance of each phosphoprotein species at each time point was quantitated and the formation of phosphoproteins was plotted as a function of time. A 
complete set of rate constants for the reaction pathway are listed in table S1. Formation of the monophosphorylated species $(0 \mathrm{P} \rightarrow 1 \mathrm{P})$ was 25 times faster with the $\mathrm{N} 546 \mathrm{~K}$ mutant $\left(0.25 \mathrm{~s}^{-1}\right)$ than with wild-type FGFR 1 kinase $\left(0.009 \mathrm{~s}^{-1}\right)$, and the data were better fit to a biphasic reaction scheme. To determine if the order of autophosphorylation is altered by the N546K point mutation, we subjected the phosphorylated species to in-gel tryptic digest and peptide mapping by liquid chromatography electrospray ionization mass spectrometry (LC/ESI-MS) and tandem mass spectrometry (MS/MS). Representative traces for peptide mapping and MS/MS sequencing are shown in fig. S2. Peptide mapping with LC/ESI-MS and MS/MS showed that, unlike the discrete order observed for wild-type FGFR1 kinase, the order of tyrosine phosphorylation observed with FGFR1 kinase harboring the N546K mutation was heterogeneous. Specifically, $\mathrm{Y}^{653}$ and $\mathrm{Y}^{583}$ were heterogeneously the first two sites phosphorylated (1P and 2P); the third site phosphorylated (3P) was $\mathrm{Y}^{585}$ in the kinase insert, and the last sites phosphorylated (4P and 5P) were a heterogeneous mixture of $\mathrm{Y}^{463}$ and $\mathrm{Y}^{654}$ found in the juxtamembrane domain and activation loop, respectively (Figs. 4 and 5). Based on the intensity of the peptide peaks for the fourth and fifth phosphorylation sites, $\mathrm{Y}^{463}$ appeared to be the preferred phosphorylation site.

Because of the inherent difficulties in determining the in vivo autophosphorylation profile of FGFR and other RTKs, the importance of ordered autophosphorylation in the context of living cells remains largely unknown. To determine whether the enhanced tyrosine kinase activity and altered order of autophosphorylation of the FGFR1_N546K mutant affects biological outcome, we established Rat-1 cells stably expressing either wild-type FGFR1 or FGFR1 harboring the N546K point mutation. Unlike cells expressing wild-type FGFR1, the N546Kexpressing cells showed morphological transformation characteristic of transformed cells characterized by decreased cell spreading and decreased adhesion to the tissue culture dish (Fig. 5C). These results suggest that mutations in the kinase domain can exert their pathogenicity in vivo.

\section{DISCUSSION}

In this report, we have explored the mechanism whereby FGFR1 kinase undergoes ordered autophosphorylation on critical tyrosine residues that function to both enhance its catalytic activity and recruit downstream signaling partners. Using intact FGFR1 kinase domains, we have shown that the order of autophosphorylation $\left(\mathrm{Y}^{463}, \mathrm{Y}^{583}, \mathrm{Y}^{585}, \mathrm{Y}^{653}, \mathrm{Y}^{654}\right.$, and $\left.\mathrm{Y}^{730}\right)$ is kinetically controlled and limited by the rate of phosphoryl transfer of the $\gamma$-phosphate group from ATP to the hydroxyl group of tyrosine. It is likely that primary structure alone does not determine the order of autophosphorylation because the amino acid sequences surrounding the tyrosine autophosphorylation sites are divergent and show minimal similarity to that of the optimal FGFR1 peptide substrate. $\mathrm{Y}^{653}$ and $\mathrm{Y}^{654}$, the critical tyrosines in the activation loop required for catalytic activity, are adjacent to one another; however, $\mathrm{Y}^{653}$ is a better substrate and is phosphorylated first. Although $\mathrm{Y}^{653}$ and $\mathrm{Y}^{583}$ have similar kinetics of phosphorylation, $\mathrm{Y}^{653}$ must be recognized first because its phosphorylation is required for enhanced catalytic activity as shown by in vitro and in vivo studies $(1,27)$. Similarly, $\mathrm{Y}^{583}$ and $\mathrm{Y}^{585}$ are separated by one amino acid; however, $\mathrm{Y}^{583}$ is phosphorylated long before $\mathrm{Y}^{585}$. The primary structure of the first three sites phosphorylated contains an acidic residue at the $\mathrm{Y}-1$ position, and steadystate kinetic experiments showed enhanced phosphorylation of both $Y^{654}$ and $Y^{585}$ when the $\mathrm{Y}-1$ position was replaced by an acidic residue. Although $\mathrm{Y}^{654}$ with a $\mathrm{Y}-1$ acidic residue had phosphorylation kinetics comparable to those of $\mathrm{Y}^{653}$, $\mathrm{Y}^{585}$ with a $\mathrm{Y}-1$ acidic residue was phosphorylated faster but at a rate much slower than that observed for $\mathrm{Y}^{583}$. This suggests that FGFR1 kinase-ordered autophosphorylation is a function of both the amino acid sequence surrounding the tyrosine phosphorylation sites and the location of the autophosphorylation sites within the overall tertiary structure (structural constraints). 
In the autophosphorylation assays, $\mathrm{Y}^{654}$ was the last site to be phosphorylated. It should be noted that $\mathrm{Y}^{654}$ is also the last site phosphorylated when a longer FGFR1 mutant containing $\mathrm{Y}^{766}$ is included (1). However, based on the data presented in this report, one would expect $\mathrm{Y}^{654}$ to be phosphorylated much earlier: The rate of $\mathrm{Y}^{654}$ phosphorylation suggests that it should be the third or fourth site phosphorylated. It does not appear that binding affinity $\left(K_{\mathrm{d}}\right)$ of $Y^{654}$ to the kinase plays a role, because the sequential phosphorylation was observed at saturation (where the reaction rate does not depend on substrate concentration). Perhaps there are subtle changes in the FGFR1 kinase structure when both $\mathrm{Y}^{653}$ and $\mathrm{Y}^{583}$ are phosphorylated that are not recapitulated in the experimental design and that decrease the ability of $\mathrm{Y}^{654}$ to be a good substrate.

In the present experimental system, it is inherently difficult to precisely measure the substrate affinity $\left(K_{\mathrm{m}}\right)$ for each of the substrates (the individual tyrosine residues), although preliminary experiments suggest that for the soluble receptor substrates, the $K_{\mathrm{m}}$ is in the low nanomolar range (fig. S3). In solution, the kinase and substrate are essentially the same molecule, and the experimental system utilized does not distinguish between heterodimers of the kinase and substrate versus homodimers of either the substrate or the kinase alone, which increases the complexity of the kinetic analysis. It is therefore likely that at subsaturating concentrations of substrate utilized to determine the $K_{\mathrm{m}}$, phosphorylation in this system cannot be explained by simple Michaelis-Menten kinetics.

Data presented here suggesting ordered autophosphorylation is intrinsically controlled by the properties of the kinase itself raise the possibility that point mutations in RTKs implicated in the pathogenesis of disease may affect the ability of a particular tyrosine to be phosphorylated by altering the microenvironment of the tyrosine, by changing the tertiary structure surrounding the tyrosine, or both. This, in turn, may change the ability of the kinase to accommodate the tyrosine and adjacent residues in the catalytic cleft and, thereby, change the order in which the kinase is phosphorylated. We investigated the order of autophosphorylation of a form of the FGFR1 kinase domain harboring a point mutation implicated in human glioblastomas and showed that an N546K mutation in the kinase core changed the order of FGFR1 kinase autophosphorylation. It is intriguing that the first and second sites phosphorylated in the N546K mutant were either $\mathrm{Y}^{583}$ in the kinase insert or $\mathrm{Y}^{653}$ in the activation loop. This suggests that the mutant had higher basal kinase activity independent of activation loop phosphorylation, a suggestion that is further supported by the greater degree of autophosphorylation observed on the native protein during expression and purification. The initial, heterogeneous phosphorylation of $\mathrm{Y}^{583}$ or $\mathrm{Y}^{653}$ interchangeably in the mutant provides additional evidence that ordered FGFR1 autophosphorylation is kinetically regulated, because both sites had similar rates of phosphorylation. Stable expression of intact FGFR1 harboring the N546K mutation in Rat-1 cells and other cell lines (fig. S4) elicited a transformed phenotype. Although it is well established that this and similar mutations in the kinase domain enhance the catalytic activity of FGFR mutants associated with pathology, it remains to be determined whether the altered order of autophosphorylation of the N546K FGFR1 mutant contributes to cell transformation by altering the program of recruitment and tyrosine phosphorylation of cellular substrates. Further biochemical characterization of the cells harboring FGFR1_N546K was not possible because of decreased adherence of the cells to the tissue culture dish under conditions of low serum concentration.

Ordered autophosphorylation of tyrosine residues in the activation loop has been observed for various tyrosine kinases $(3-7,35)$, and data presented here suggest a general mechanism for all RTKs in which sequential autophosphorylation of tyrosine residues both in the activation loop and on other portions of the kinase domain is kinetically controlled, with the order of phosphorylation a function of the location of the tyrosine within both the primary and the tertiary structure. This report also suggests that ordered autophosphorylation may have a 
physiologically relevant role in vivo for the temporal recruitment of downstream signaling partners.

\section{MATERIALS AND METHODS}

\section{Chemical reagents}

ATP, $\mathrm{MgCl}_{2}$, ammonium acetate (99.99\%), ammonium bicarbonate $\left(\mathrm{NH}_{4} \mathrm{HCO}_{3}\right)$, EDTA, Hepes, and ammonium acetate were purchased from Sigma. Trypsin Gold mass spectrometry grade was obtained from Promega. High-performance liquid chromatography-grade acetonitrile (ACN) and water were from J. T Baker. Trifluoroacetic acid and Slide-A-Lyzer dialysis cassettes $(0.5-3 \mathrm{ml}, 3500$ molecular weight cutoff) were purchased from Pierce. The C18-packed PicoFrit column ( $75 \mu \mathrm{m}$ outer diameter, $15 \mu \mathrm{m}$ inside diameter) was obtained from New Objectives. $\left[\gamma_{-}{ }^{32} \mathrm{P}\right]$ ATP was obtained from GE Healthcare (Piscataway, NJ).

\section{FGFR1 kinase purification in unphosphorylated and phosphorylated forms}

FGFR1 wild-type kinase (FGFR1K) domain was purified as previously described $(1,36)$. A mutant form of FGFR1 kinase domain with three tyrosine to phenylalanine mutations (FGFR1K-3F) was purified as previously described in both the unphosphorylated and the phosphorylated forms (1).

\section{Kinase-dead FGFR1 mutant}

For the kinase-dead constructs, a single aspartic acid to alanine mutation, D623A, was introduced by site-directed mutagenesis (Stratagene) to make the kinase inactive. In each construct, four of the five tyrosines were mutated to phenylalanine by sequential site-directed mutagenesis steps. In the case of the $\mathrm{Y}^{653} / \mathrm{Y}^{654} \mathrm{KD}$ construct, only three sites were mutated to phenylalanine, leaving the two activation loop tyrosines free to be phosphorylated. Kinasedead substrates were purified as described for wild-type kinase. The phosphorylated form, $\mathrm{pY}^{653} / \mathrm{Y}^{654} \mathrm{KD}$, was obtained by incubating $13.8 \mu \mathrm{M}$ phosphorylated wild-type kinase (FGFR1K-4P/5P mixture), $138.8 \mu \mathrm{M} \mathrm{Y}{ }^{653} / \mathrm{Y}^{654} \mathrm{KD}, 10 \mathrm{mM}$ ATP, and $25 \mathrm{mM} \mathrm{MgCl} 2$ at $4{ }^{\circ} \mathrm{C}$ for 1 hour (final concentrations). The reaction was quenched with $50 \mathrm{mM}$ EDTA to stop the reaction. The monophosphorylated form, $\mathrm{pY}^{653} / \mathrm{Y}^{654} \mathrm{KD}$, was initially purified by gelfiltration chromatography on a Superdex 200 HR10/30 (GE Healthcare, Piscataway, NJ) to remove nucleotides and EDTA and subsequently separated from the unphosphorylated, bisphosphorylated, and wild-type prephosphorylated kinase by anion-exchange chromatography on a MonoQ HR 16/10 (GE Healthcare, Piscataway, NJ). The purity and location of the phosphate group was verified by native gel electrophoresis and mass spectrometry. A kinase assay was performed to verify kinase inactive status by incubating $30 \mu \mathrm{M}$ kinase-dead substrate, $5 \mathrm{mM}$ ATP, and $10 \mathrm{mM} \mathrm{MgCl}_{2}$ in $20 \mathrm{mM}$ Hepes buffer, $\mathrm{pH} 7.4$, for various reaction times, and the reaction was quenched with $50 \mathrm{mM}$ EDTA (final concentrations). Samples were separated by native gel electrophoresis to visualize the formation of differentially phosphorylated species.

\section{Native gel electrophoresis}

A $7 \%$ tris- $\mathrm{HCl}$ native gel was used to separate the differentially phosphorylated species present in samples generated by the substrate phosphorylation experiments. The $\mathrm{pH}$ of the separating gel was 8.8 and the $\mathrm{pH}$ of the stacking gel was 6.8. The relative intensities of the phosphorylated and unphosphorylated species were quantitated by densitometric analysis performed with a UVP Epi Chemi II Darkroom (Labworks). Data were plotted and analyzed with Graphpad Prism 4. 


\section{FGFR1 kinase substrate phosphorylation}

Kinase assays were initiated by combining, at final concentrations, $0.1 \mu \mathrm{M}$ FGFR1-3F-2P kinase, 10,15 , or $30 \mu \mathrm{M}$ kinase-dead substrate, $5 \mathrm{mM} \mathrm{ATP}$, and $10 \mathrm{mM} \mathrm{MgCl}_{2}$ at $25^{\circ} \mathrm{C}$ for various times. Reactions were quenched with $83 \mathrm{mM}$ EDTA. Kinase, substrates, nucleotides, and quench buffer were made in $10 \mathrm{mM}$ Hepes (pH 7.4). Reaction samples were visualized by native gel electrophoresis.

\section{Pre-steady-state burst kinetics}

Rapid chemical quench experiments were performed with a KinTek RFQ-3 Rapid Chemical Quench Apparatus (Kintek Corporation, Austin, TX) at $25^{\circ} \mathrm{C}$. The concentrations of the enzyme and substrates cited in the text are those after mixing and during the reaction. The reaction was initiated by mixing a solution containing kinase-dead substrate $\left(\mathrm{Y}^{463} \mathrm{KD}\right)$ and $\left[\gamma^{-}{ }^{32} \mathrm{P}\right] \mathrm{ATP} / \mathrm{MgCl}_{2}(15 \mu \mathrm{l})$ with a solution containing fully phosphorylated kinase (FGFR1-3F-2P). For these experiments, $3 \mu \mathrm{M}$ phosphorylated kinase (FGFR1K-3F-2P), 9, 15, or $30 \mu \mathrm{M} \mathrm{Y}{ }^{463} \mathrm{KD}$ substrate, $5 \mathrm{mM}$ ATP $\left(0.25 \mu \mathrm{Ci} / \mu \mathrm{l}\left[\gamma_{-}{ }^{32} \mathrm{P}\right] \mathrm{ATP}\right)$, and $10 \mathrm{mM} \mathrm{MgCl}{ }_{2}$ in 10 $\mathrm{mM}$ Hepes ( $\mathrm{pH}$ 7.4), final concentrations were used. After various reaction times, the reaction mixture was quenched with $83 \mathrm{mM}$ EDTA. Samples were resolved by SDS-polyacrylamide gel electrophoresis (PAGE) and quantitated by PhosphorImager analysis (Image Quant, Molecular Dynamics Storm 820). Zero time points were determined by addition of EDTA to enzyme solution before mixing with substrate and were used for background correction. Data were fit by nonlinear regression in GraphPad Prism 4 to both burst equation and singleexponential equation.

\section{Identification of tyrosine phosphorylation sites by LC/ESI-MS/MS}

The electrophoretic bands from native-gel analysis corresponding to unphosphosphorylated and different phosphorylated states were excised and in-gel trypsin digestion was performed. The resulting tryptic digest (Trypsin Gold, Promega) for each phosphorylation state was further analyzed by nano-LC (Dionex Ultimate3000 System) coupled to a Thermo ESI LTQ mass spectrometer. A typical gradient was run for $60 \mathrm{~min}$ from 0 to $100 \%$ solvent $\mathrm{B}(80 \% \mathrm{ACN}$, $20 \% \mathrm{H}_{2} \mathrm{O}$, and $0.1 \%$ formic acid). Solvent A consisted of 5\% ACN, $95 \% \mathrm{H}_{2} \mathrm{O}$, and $0.1 \%$ formic acid. The flow rate was set at $200 \mathrm{nl} / \mathrm{min}$ on a $75 \mu \mathrm{m}$ by $10 \mathrm{~cm}$ fused silica capillary column (New Objectives) inhouse packed with Michrom Magic C18AQ (200 ̊, $5 \mu \mathrm{m})$. The ESI LTQ mass spectrometer was operated in selected ion monitoring mode for precursor ions corresponding to the peptides containing unphosphorylated and phosphorylated tyrosine residues. The peptide identification was performed automatically with the Bioworks 3.1 software. The generated peptide list was ranked by XCorr to charge state ratio and the phosphorylation sites were identified for each phosphorylation state.

\section{Glioblastoma FGFR1 mutant purification and autophosphorylation by rapid chemical quench}

The N546K glioblastoma point mutation was introduced by site-directed mutagenesis (Stratagene) into wild-type FGFR1K and purified following the protocol used for the wildtype kinase. Rapid chemical quench experiments were performed with a Kintek RFQ-3 Rapid Chemical Quench (Kintek Instruments). A final enzyme concentration of $35 \mu \mathrm{M}$ was utilized. The reaction was initiated by mixing the enzyme solution with ATP and $\mathrm{MgCl}_{2}, 5 \mathrm{mM}$ and 10 $\mathrm{mM}$ final concentration, respectively, and then quenching the reaction with $100 \mathrm{mM}$ EDTA at different reaction times. The enzyme, ATP, $\mathrm{MgCl}_{2}$, and EDTA were prepared in $10 \mathrm{mM}$ Hepes ( $\mathrm{pH} 7.4)$. 


\section{Kinetic modeling of FGFR1K wild type and FGFR1K_N546K autophosphorylation reaction}

Kinetic modeling of FGFR1K wild-type and glioblastoma mutant autophosphorylation was performed based on the densitometric analysis of the samples separated by native PAGE. The simulations were performed with KinTekSim and FitSim software (Kintek Instruments).

\section{Cell culture assays}

Rat-1 cells were stably infected with pBabe-puro constructs encoding either wild-type FGFR1 or FGFR1 harboring an N546K point mutation. Cell lines were maintained in Dulbecco's modified minimum essential medium supplemented with $10 \%$ fetal calf serum, $100 \mu \mathrm{g}$ each of penicillin and streptomycin (Gibco BRL), and puromycin $(2.5 \mu \mathrm{g} / \mathrm{ml})$.

\section{Supplementary Material}

Refer to Web version on PubMed Central for supplementary material.

\section{Acknowledgments}

This work was supported by NIH grants RO1-AR051448, RO1-AR051886, and P50AR054086 to J.S. and NIH grants R21 CA 125284 and R01 CA127580 to K.S.A.

\section{REFERENCES AND NOTES}

1. Furdui CM, Lew ED, Schlessinger J, Anderson KS. Autophosphorylation of FGFR1 kinase is mediated by a sequential and precisely ordered reaction. Mol. Cell 2006;21:711-717. [PubMed: 16507368]

2. Abbreviations for the amino acid residues are as follows:Ala A, Cys C, Asp D, Glu E, Phe F, Gly G, His H, Ile I, Lys K, Leu L, Met M, Asn N, Pro P, Gln Q, Arg R, Ser S, Thr T, Val V, Trp W, Tyr Y. $\mathrm{X}$ represents any amino acid.

3. Dickens M, Tavaré JM. Analysis of the order of autophosphorylation of human insulin receptor tyrosines 1158, 1162 and 1163. Biochem. Biophys. Res. Commun 1992;186:244-250. [PubMed: 1321605]

4. Wei L, Hubbard SR, Hendrickson WA, Ellis L. Expression, characterization, and crystallization of the catalytic core of the human insulin receptor protein-tyrosine kinase domain. J. Biol. Chem 1995;270:8122-8130. [PubMed: 7713916]

5. Favelyukis S, Till JH, Hubbard SR, Miller WT. Structure and autoregulation of the insulin-like growth factor 1 receptor kinase. Nat. Struct. Biol 2001;8:1058-1063. [PubMed: 11694888]

6. Murray BW, Padrique ES, Pinko C, McTigue MA. Mechanistic effects of autophosphorylation on receptor tyrosine kinase catalysis: Enzymatic characterization of Tie2 and phospho-Tie2. Biochemistry 2001;40:10243-10253. [PubMed: 11513602]

7. Till JH, Becerra M, Watty A, Lu Y, Ma Y, Neubert TA, Burden SJ, Hubbard SR. Crystal structure of the MuSK tyrosine kinase: Insights into receptor autoregulation. Structure 2002;10:1187-1196. [PubMed: 12220490]

8. Blagoev B, Ong S-E, Kratchmarova I, Mann M. Temporal analysis of phosphotyrosine-dependent signaling networks by quantitative proteomics. Nat. Biotechnol 2004;22:1139-1145. [PubMed: 15314609]

9. Schmelzle K, Kane S, Gridley S, Lienhard GE, White FM. Temporal dynamics of tyrosine phosphorylation in insulin signaling. Diabetes 2006;55:2171-2179. [PubMed: 16873679]

10. Ibarrola N, Molina H, Iwahori A, Pandey A. A novel proteomic approach for specific identification of tyrosine kinase substrates using $\left[{ }^{13}\right.$ C]tyrosine. J. Biol. Chem 2004;279:15805-15813. [PubMed: 14739304]

11. Zhang Y, Wolf-Yadlin A, Ross PL, Pappin DJ, Rush J, Lauffenburger DA, White FM. Time-resolved mass spectrometry of tyrosine phosphorylation sites in the epidermal growth factor receptor signaling network reveals dynamic modules. Mol. Cell. Proteomics 2005;4:1240-1250. [PubMed: 15951569] 
12. Zhu H, Klemic JF, Chang S, Bertone P, Casamayor A, Klemic KG, Smith D, Gerstein M, Reed MA, Snyder M. Analysis of yeast protein kinases using protein chips. Nat. Genet 2000;26:283-289. [PubMed: 11062466]

13. Ptacek J, Devgan G, Michaud G, Zhu H, Zhu X, Fasolo J, Guo H, Jona G, Breitkreutz A, Sopko R, McCartney RR, Schmidt MC, Rachidi N, Lee S-J, Mah AS, Meng L, Stark MJR, Stern DF, De Virgilio C, Tyers M, Andrews B, Gerstein M, Schweitzer B, Predki PF, Snyder M. Global analysis of protein phosphorylation in yeast. Nature 2005;438:679-684. [PubMed: 16319894]

14. Songyang Z, Blechner S, Hoagland N, Hoekstra MF, Piwnica-Worms H, Cantley LC. Use of an oriented peptide library to determine the optimal substrates of protein kinases. Curr. Biol 1994;4:973982. [PubMed: 7874496]

15. Songyang Z, Carraway KL III, Eck MJ, Harrison SC, Feldman RA, Mohammadi M, Schlessinger J, Hubbard SR, Smith DP, Eng C, Lorenzo MJ, Ponder BAJ, Mayer BJ, Cantley LC. Catalytic specificity of protein-tyrosine kinases is critical for selective signalling. Nature 1995;373:536-539. [PubMed: 7845468]

16. Hutti JE, Jarrell ET, Chang JD, Abbott DW, Storz P, Toker A, Cantley LC, Turk BE. A rapid method for determining protein kinase phosphorylation specificity. Nat. Methods 2004;1:27-29. [PubMed: 15782149]

17. Obenauer JC, Cantley LC, Yaffe MB. Scansite 2.0: Proteome-wide prediction of cell signaling interactions using short sequence motifs. Nucleic Acids Res 2003;31:3635-3641. [PubMed: 12824383]

18. Ablooglu AJ, Till JH, Kim K, Parang K, Cole PA, Hubbard SR, Kohanski RA. Probing the catalytic mechanism of the insulin receptor kinase with a tetrafluorotyrosine-containing peptide substrate. J. Biol. Chem 2000;275:30394-30398. [PubMed: 10869355]

19. Hubbard SR. Crystal structure of the activated insulin receptor tyrosine kinase in complex with peptide substrate and ATP analog. EMBO J 1997;16:5572-5581. [PubMed: 9312016]

20. Levinson NM, Kuchment O, Shen K, Young MA, Koldobskiy M, Karplus M, Cole PA, Kuriyan J. A Src-like inactive conformation in the Abl tyrosine kinase domain. PLoS Biol 2006;4:e144. [PubMed: 16640460]

21. Sondhi D, Xu W, Songyang Z, Eck MJ, Cole PA. Peptide and protein phosphorylation by protein tyrosine kinase Csk: Insights into specificity and mechanism. Biochemistry 1998;37:165-172. [PubMed: 9425036]

22. Songyang Z, Cantley LC. Recognition and specificity in protein tyrosine kinase-mediated signalling. Trends Biochem. Sci 1995;20:470-475. [PubMed: 8578591]

23. Adams JA. Kinetic and catalytic mechanisms of protein kinases. Chem. Rev 2001;101:2271-2290. [PubMed: 11749373]

24. Matte A, Tari LW, Delbaere LT. How do kinases transfer phosphoryl groups? Structure 1998;6:413419. [PubMed: 9562560]

25. Valiev M, Kawai R, Adams JA, Weare JH. The role of the putative catalytic base in the phosphoryl transfer reaction in a protein kinase: First-principles calculations. J. Am. Chem. Soc 2003;125:99269927. [PubMed: 12914447]

26. Madhusudan, Trafny EA, Xuong NH, Adams JA, Ten Eyck LF, Taylor SS, Sowadski JM. cAMPdependent protein kinase: Crystallographic insights into substrate recognition and phosphotransfer. Protein Sci 1994;3:176-187. [PubMed: 8003955]

27. Mohammadi M, Dikic I, Sorokin A, Burgess WH, Jaye M, Schlessinger J. Identification of six novel autophosphorylation sites on fibroblast growth factor receptor 1 and elucidation of their importance in receptor activation and signal transduction. Mol. Cell. Biol 1996;16:977-989. [PubMed: 8622701]

28. Grant BD, Adams JA. Pre-steady-state kinetic analysis of cAMP-dependent protein kinase using rapid quench flow techniques. Biochemistry 1996;35:2022-2029. [PubMed: 8639687]

29. Ablooglu AJ, Kohanski RA. Activation of the insulin receptor's kinase domain changes the ratedetermining step of substrate phosphorylation. Biochemistry 2001;40:504-513. [PubMed: 11148045]

30. Jan AY, Johnson EF, Diamonti AJ, Carraway KL III, Anderson KS. Insights into the HER-2 receptor tyrosine kinase mechanism and substrate specificity using a transient kinetic analysis. Biochemistry 2000;39:9786-9803. [PubMed: 10933796] 
31. Hubbard SR, Mohammadi M, Schlessinger J. Autoregulatory mechanisms in protein-tyrosine kinases. J. Biol. Chem 1998;273:11987-11990. [PubMed: 9575136]

32. Rand V, Huang J, Stockwell T, Ferriera S, Buzko O, Levy S, Busam D, Li K, Edwards JB, Eberhart C, Murphy KM, Tsiamouri A, Beeson K, Simpson AJG, Venter JC, Riggins GJ, Strausberg RL. Sequence survey of receptor tyrosine kinases reveals mutations in glioblastomas. Proc. Natl. Acad. Sci. U.S.A 2005;102:14344-14349. [PubMed: 16186508]

33. Chen H, Ma J, Li W, Eliseenkova AV, Xu C, Neubert TA, Miller WT, Mohammadi M. A molecular brake in the kinase hinge region regulates the activity of receptor tyrosine kinases. Mol. Cell 2007;27:717-730. [PubMed: 17803937]

34. Lew ED, Bae JH, Rohmann E, Wollnik B, Schlessinger J. Structural basis for reduced FGFR2 activity in LADD syndrome: Implications for FGFR autoinhibition and activation. Proc. Natl. Acad. Sci. U.S.A 2007;104:19802-19807. [PubMed: 18056630]

35. White MF, Shoelson SE, Keutmann H, Kahn CR. A cascade of tyrosine autophosphorylation in the $\beta$-subunit activates the phosphotransferase of the insulin receptor. J. Biol. Chem 1988;263:29692980. [PubMed: 2449432]

36. Mohammadi M, Schlessinger J, Hubbard SR. Structure of the FGF receptor tyrosine kinase domain reveals a novel autoinhibitory mechanism. Cell 1996;86:577-587. [PubMed: 8752212] 
A

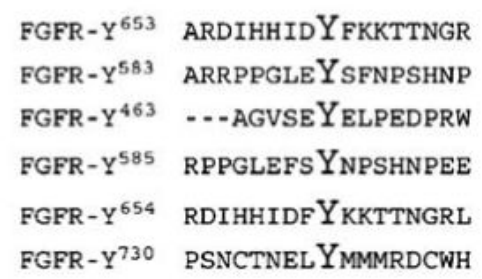

FGFR $-Y^{653}$ ARDIHHIDYFKKTTNGR

FGFR $-Y^{583}$ ARRPPGLEYSFNPSHNP

FGFR $-Y^{463} \quad \cdots$-AGVSEYELPEDPRW

FGFR $-Y^{730}$ PSNCTNEL YMMMRDCWH

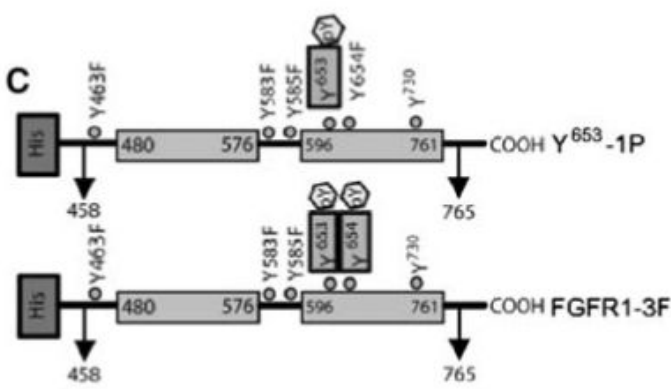

B
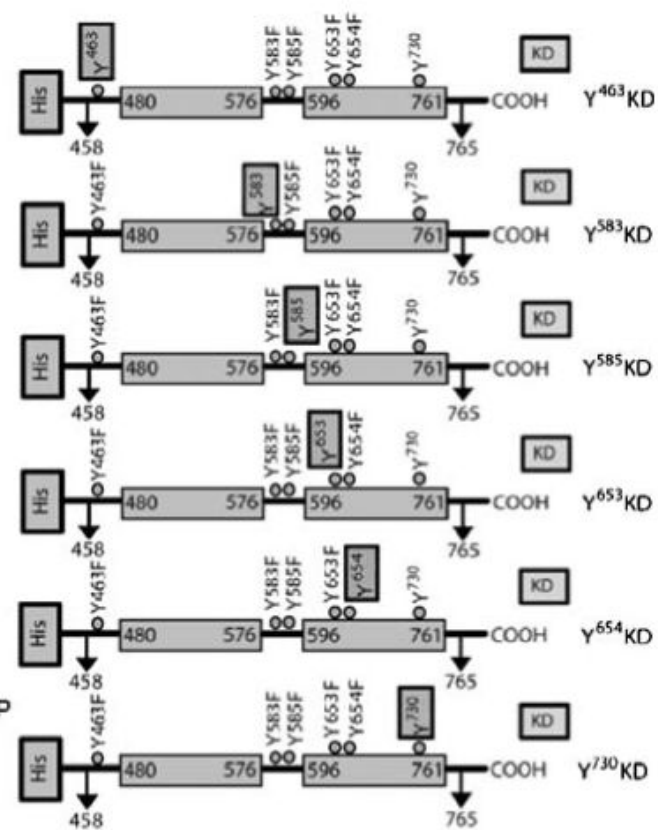

D

E
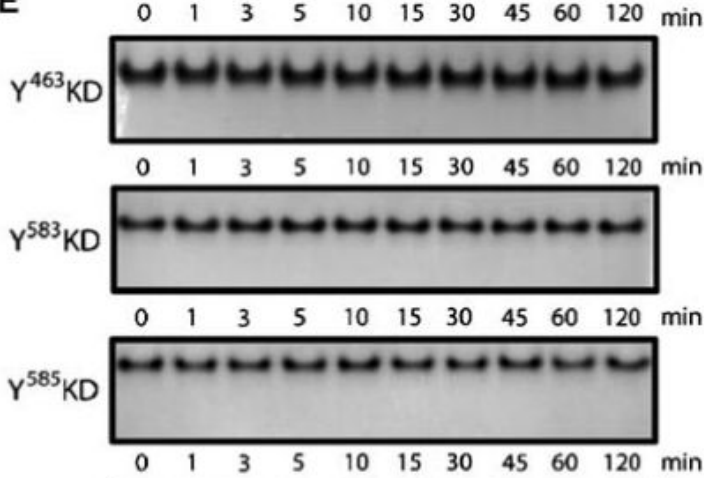

$\mathrm{Y}^{653} \mathrm{KD}$

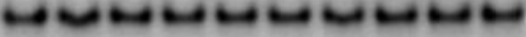

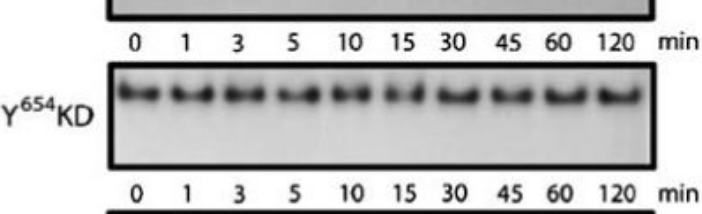

$\mathrm{Y}^{730} \mathrm{KD}$

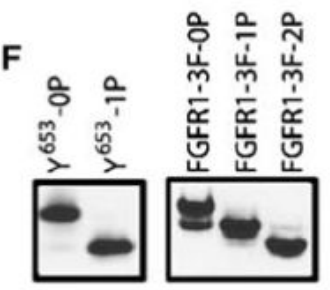

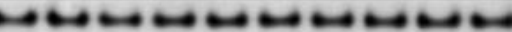

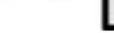

Fig. 1.

Amino acid alignment of tyrosine phosphorylation sites and overview of FGFR1 kinase constructs. (A) Aminoacid alignment of FGFR1 tyrosine kinase autophosphorylation sites according to the observed order of phosphorylation. Phosphorylation of $\mathrm{Y}^{730}$ was not observed in this system. (B) Diagram of His-tagged, kinase-dead FGFR1 substrates, each with a single tyrosine phosphorylation site as indicated by the construct number. In the first five substrates, four other tyrosines are mutated to phenylalanine, and in the $\mathrm{Y}^{730} \mathrm{KD}$ construct, five tyrosines are mutated to phenylalanine as indicated by a $\mathrm{Y} \rightarrow \mathrm{F}$ mutation. Constructs were made kinasedead by mutation of the catalytic base, D623A. (C) A schematic diagram of FGFR1 kinaseactive domains used for phosphorylation of the kinase-dead substrates. The 
monophosphorylated form $\left(\mathrm{Y}^{653}-1 \mathrm{P}\right)$ is phosphorylated at $\mathrm{Y}^{653}$ and the bis-phosphorylated form (FGFR-3F-2P) is phosphorylated at both $\mathrm{Y}^{653}$ and $\mathrm{Y}^{654}$. (D) Native gel electrophoresis of purified FGFR1 kinase-dead substrates. (E) Kinase assay of FGFR1 kinase-dead substrates. The different substrates $\left(30 \mu \mathrm{M}\right.$ final concentration) were incubated at $25^{\circ} \mathrm{C}$ with ATP and $\mathrm{MgCl}_{2}$ to a final concentration of 5 and $10 \mathrm{mM}$, respectively. The reaction was quenched at different reaction times with $50 \mathrm{mM}$ EDTA, final. Reaction samples were separated by native gel electrophoresis to observe the formation of phosphorylated species. Autophosphorylation of the kinase-dead samples was not observed. (F) Native gel electrophoresis of purified FGFR kinase-active domains in either a monophosphorylated $\left(\mathrm{Y}^{653}-1 \mathrm{P}\right)$ or a bis-phosphorylated (FGFR1-3F-2P) state as shown by the gel shift. 
$\begin{array}{llllllllllll}\text { A } & 0 & 3 & 5 & 10 & 15 & 30 & 45 & 60 & 90 & 120 & \mathrm{~min}\end{array}$
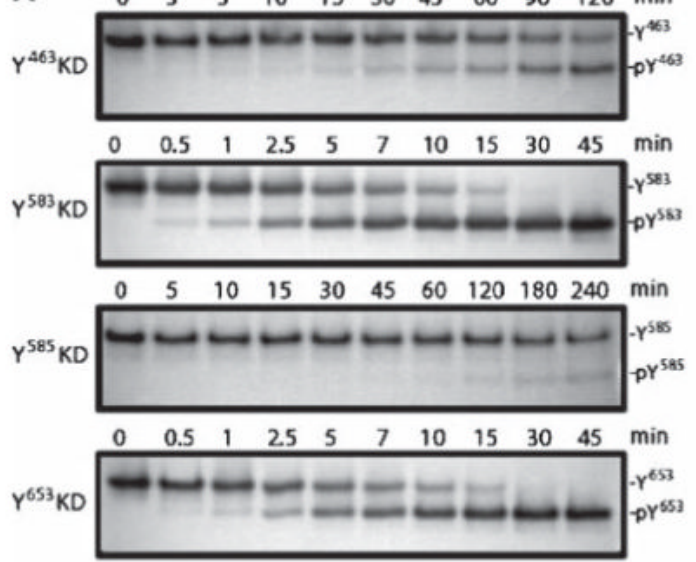

\begin{tabular}{llllllllll}
0 & 3 & 5 & 10 & 15 & 30 & 45 & 60 & 90 & 120 \\
\hline
\end{tabular}
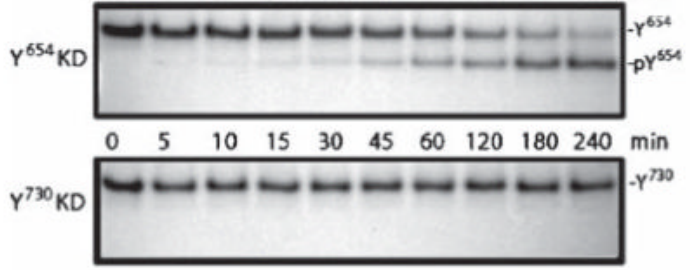

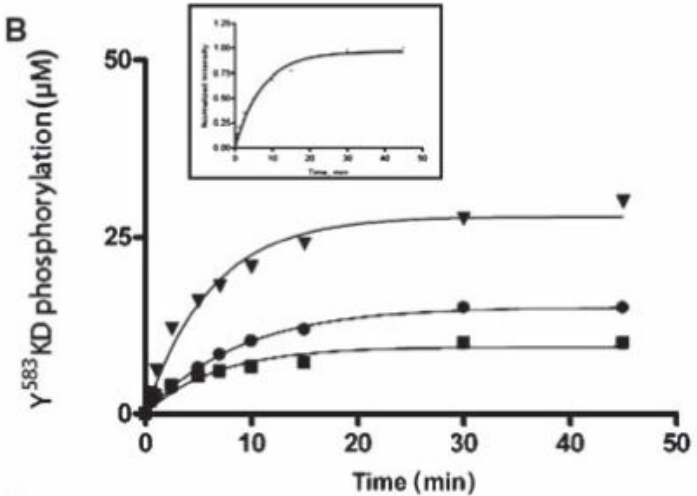

C

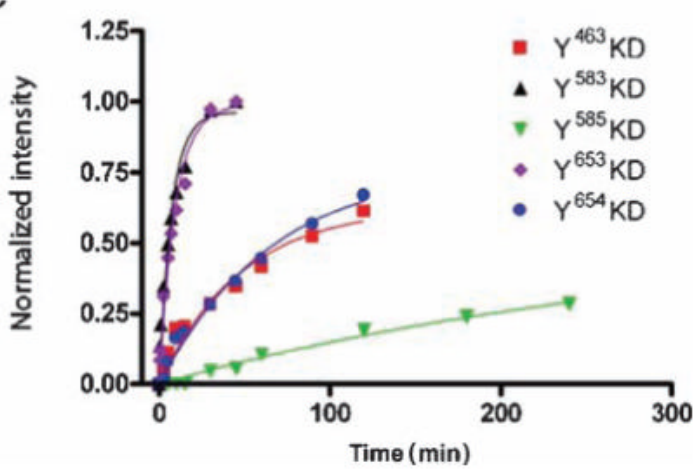

Fig. 2.

Quantitative analysis of phosphorylation of individual FGFR1 kinase domain tyrosine sites. (A) Phosphorylation of FGFR1 kinase-dead substrates by fully activated FGFR1 kinase. FGFR1-3F-2P $(0.1 \mu \mathrm{M})$ was reacted with saturating concentration of FGFR1 kinase-dead substrate ( $10 \mu \mathrm{M}$ shown), $5 \mathrm{mM} \mathrm{ATP}$, and $10 \mathrm{mM} \mathrm{MgCl}_{2}$ at $25^{\circ} \mathrm{C}$ for various amounts of time. Reactions were quenched upon addition of $50 \mathrm{mM}$ EDTA and the phosphorylation states of the kinase-dead substrate at each time point separated by native gel electrophoresis. The amount of active kinase is below the limit of detection and cannot be seen on the gels. (B)

Representative quantitative analysis of FGFR1-3F-2P-mediated phosphorylation of $\mathrm{Y}^{583} \mathrm{KD}$ substrate at three saturating concentrations of substrate: (घ) $10 \mu \mathrm{M}$ (reaction rate, 0.1523 $\min ^{-1}$ ), (•) $15 \mu \mathrm{M}$ (reaction rate, $0.1139 \mathrm{~min}^{-1}$ ), and ( $\left.\boldsymbol{\nabla}\right) 30 \mu \mathrm{M}$ (reaction rate, $0.1628 \mathrm{~min}^{-1}$ ). Data at the three concentrations were similar and averaged (inset). (C) Quantitative comparison of FGFR1-3F-2P-mediated phosphorylation of the five kinase-dead substrates. Shown is the average of the data obtained from the three saturating concentrations of each substrate.

Calculated average rates of phosphorylation are as follows: $\left(\boldsymbol{a}\right.$, red) $\mathrm{Y}^{463} \mathrm{KD}, 0.0209 \pm 0.004$ $\min ^{-1} ;\left(\boldsymbol{\Delta}\right.$, black) $\mathrm{Y}^{583} \mathrm{KD}, 0.1388 \pm 0.016 \mathrm{~min}^{-1} ;(\boldsymbol{\nabla}$, green $) \mathrm{Y}^{585} \mathrm{KD}, 0.0032 \pm 0.001$ $\min ^{-1}$; $\left(\diamond\right.$, purple) $\mathrm{Y}^{653} \mathrm{KD}, 0.1080 \pm 0.010 \mathrm{~min}^{-1}$; and $(\bullet$, blue $) \mathrm{Y}^{654} \mathrm{KD}, 0.0151 \pm 0.002$ $\min ^{-1}$. Data were fit to a single-exponential equation in Graphpad. 
A

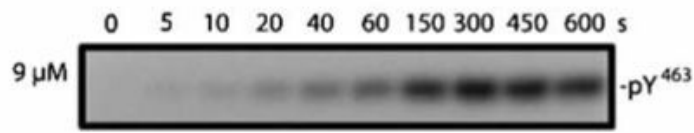

$\begin{array}{llllllllll}0 & 5 & 10 & 20 & 40 & 60 & 150 & 300 & 450 & 600 \mathrm{~s}\end{array}$

$15 \mu \mathrm{M}$
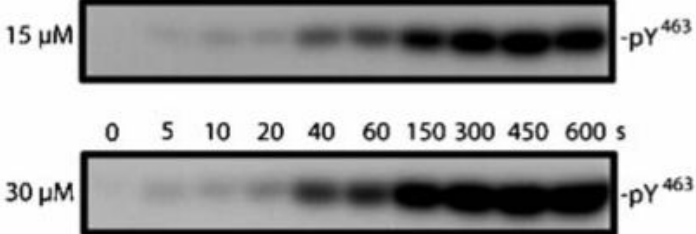

C

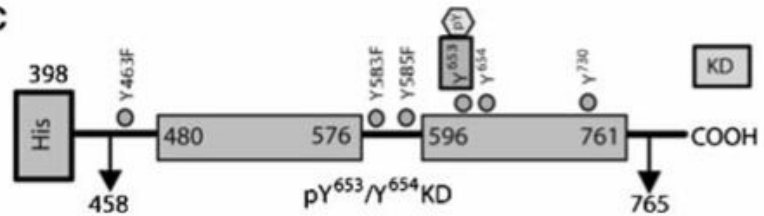

D
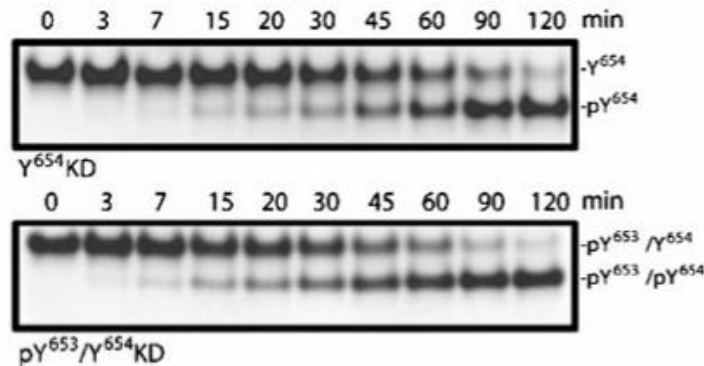

$\mathbf{F}$

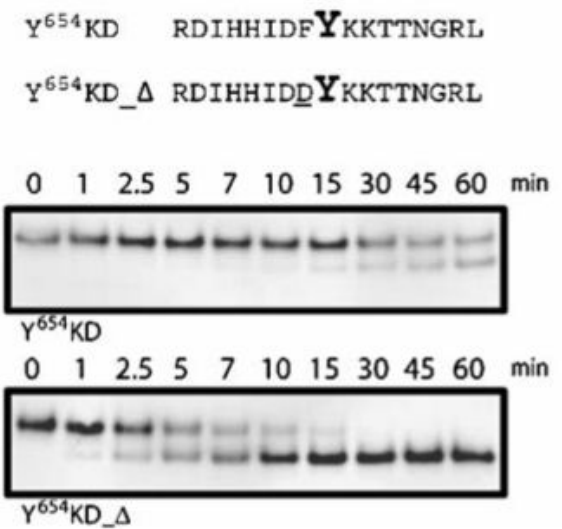

B

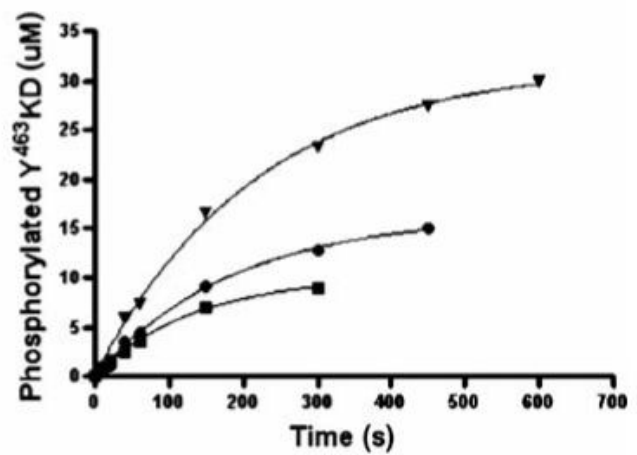

E

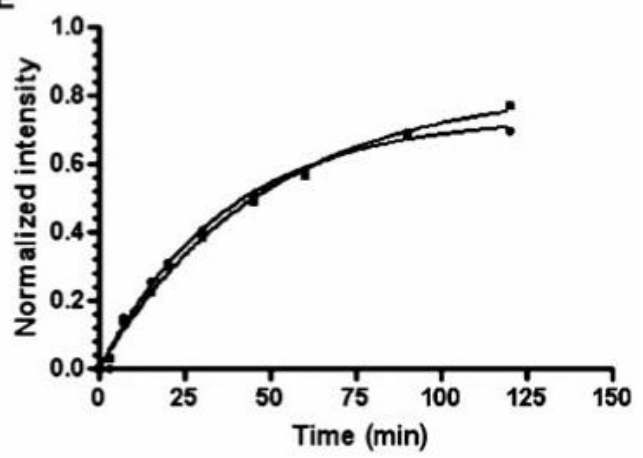

G $\mathrm{Y}^{585} \mathrm{KD}$ RPPGLEFS $Y_{\text {NPSHNPEE }}$
$\mathrm{Y}^{585}{ }_{\mathrm{KD}} \triangle \mathrm{RPPGLSFE} \mathrm{Y}_{\text {NPSHNPEE }}$

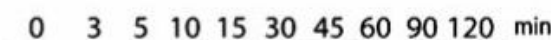

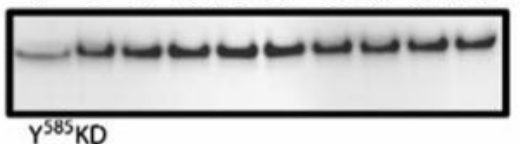

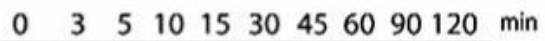

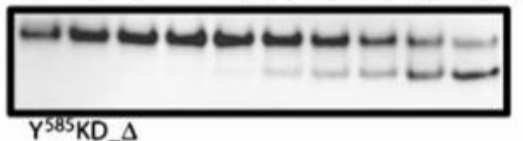

Fig. 3.

Kinetic regulation of FGFR1 autophosphorylation. (A) Phosphorylation of kinase-dead substrate by fully activated kinase. FGFR1-3F-2P kinase ( $3 \mu \mathrm{M})$ was incubated with 3-fold (9 $\mu \mathrm{M}), 5$-fold $(15 \mu \mathrm{M})$, and 10 -fold $(30 \mu \mathrm{M})$ excess $\mathrm{Y}^{463} \mathrm{KD}$ substrate in the presence of $5 \mathrm{mM}$ $\left[\gamma-{ }^{32} \mathrm{P}\right] \mathrm{ATP}$ and $10 \mathrm{mM} \mathrm{MgCl} 2$ in a rapid chemical quench apparatus. The formation of the monophosphorylated species over time was followed by incorporation of radiolabeled phosphate. (B) Quantitative analysis of $\mathrm{Y}^{463} \mathrm{KD}$ phosphorylation by FGFR1-3F-2P kinase. The data were fit in Graphpad to a single-exponential equation and did not converge to the burst equation. Reaction rates for 3-( $\bullet), 5-(\bullet)$, and 10-fold ( $\boldsymbol{\nabla})$ excess substrate were 0.007 $\pm 0.0004,0.005 \pm 0.0003$, and $0.004 \pm 0.0003 \mathrm{~s}^{-1}$, respectively. (C) Schematic of $\mathrm{pY}^{653}$ / 
$\mathrm{Y}^{654} \mathrm{KD}$ substrate phosphorylated at $\mathrm{Y}^{653}$ with $\mathrm{Y}^{654}$ site unphosphorylated. The other three tyrosine sites are mutated to phenylalanine. (D) Phosphorylation of kinase-dead substrates $\mathrm{Y}^{654} \mathrm{KD}$ and $\mathrm{pY} \mathrm{Y}^{63} / \mathrm{Y}^{654}$ by fully activated kinase FGFR1-3F-2P. FGFR1-3F-2P $(0.1 \mu \mathrm{M})$ was reacted with saturating concentration of FGFR1 kinase-dead substrate $(30 \mu \mathrm{M}), 5 \mathrm{mM}$ ATP, and $10 \mathrm{mM} \mathrm{MgCl}_{2}$ for various amounts of time. Reactions were quenched with $50 \mathrm{mM}$ EDTA and the phosphorylation states of the kinase-dead substrate at each time point were separated by native gel electrophoresis. The amount of the active kinase is below the limit of detection and cannot be seen on the gels. (E) Quantitative analysis of FGFR1-3F-2P-mediated phosphorylation of $\mathrm{pY}^{653} / \mathrm{Y}^{654} \mathrm{KD}$ and $\mathrm{Y}^{654} \mathrm{KD}$. Shown are the average data obtained from two saturating concentrations of substrate: 15 and $30 \mu \mathrm{M}$. $\mathrm{Y}^{654} \mathrm{KD}(\boldsymbol{\bullet})$ and $\mathrm{pY}^{653} / \mathrm{Y}^{654} \mathrm{KD}(\bullet)$ were phosphorylated at a rate of $0.0209 \pm 0.001$ and $0.0271 \pm 0.002 \mathrm{~min}^{-1}$, respectively. $(\mathbf{F})$ Phosphorylation of kinase-dead substrates $\mathrm{Y}^{654} \mathrm{KD}$ and $\mathrm{Y}^{654} \mathrm{KD} \_\Delta$ (containing a $\mathrm{Y} 653 \mathrm{D}$ point mutation) by fully activated kinase FGFR1-3F-2P. FGFR1-3F-2P $(0.1 \mu \mathrm{M})$ was reacted with saturating concentration of FGFR1 kinase-dead substrate $(30 \mu \mathrm{M}), 5 \mathrm{mM}$ ATP, and $10 \mathrm{mM}$ $\mathrm{MgCl}_{2}$ for various amounts of time. Reactions were quenched with $50 \mathrm{mM}$ EDTA, and phosphorylated and unphosphorylated forms of kinase-dead substrate at each time point were separated by native gel electrophoresis. (G) Phosphorylation of kinase-dead substrates $\mathrm{Y}^{585} \mathrm{KD}$ and $\mathrm{Y}^{585} \mathrm{KD} \_\Delta$ (with $\mathrm{Y}-1$ position of $\mathrm{Y}^{583}$ and $\mathrm{Y}^{585}$ swapped) by fully activated kinase FGFR1-3F-2P. FGFR1-3F-2P $(0.1 \mu \mathrm{M})$ was reacted with saturating concentration of FGFR1 kinase-dead substrate $(30 \mu \mathrm{M}), 5 \mathrm{mM}$ ATP, and $10 \mathrm{mM} \mathrm{MgCl}_{2}$ for various amounts of time. Reactions were quenched with $50 \mathrm{mM}$ EDTA and phosphorylated and unphosphorylated forms of the kinase-dead substrate at each time point were separated by native gel electrophoresis. In both cases, the amount of active kinase is below the limit of detection and cannot be seen on the gels. 

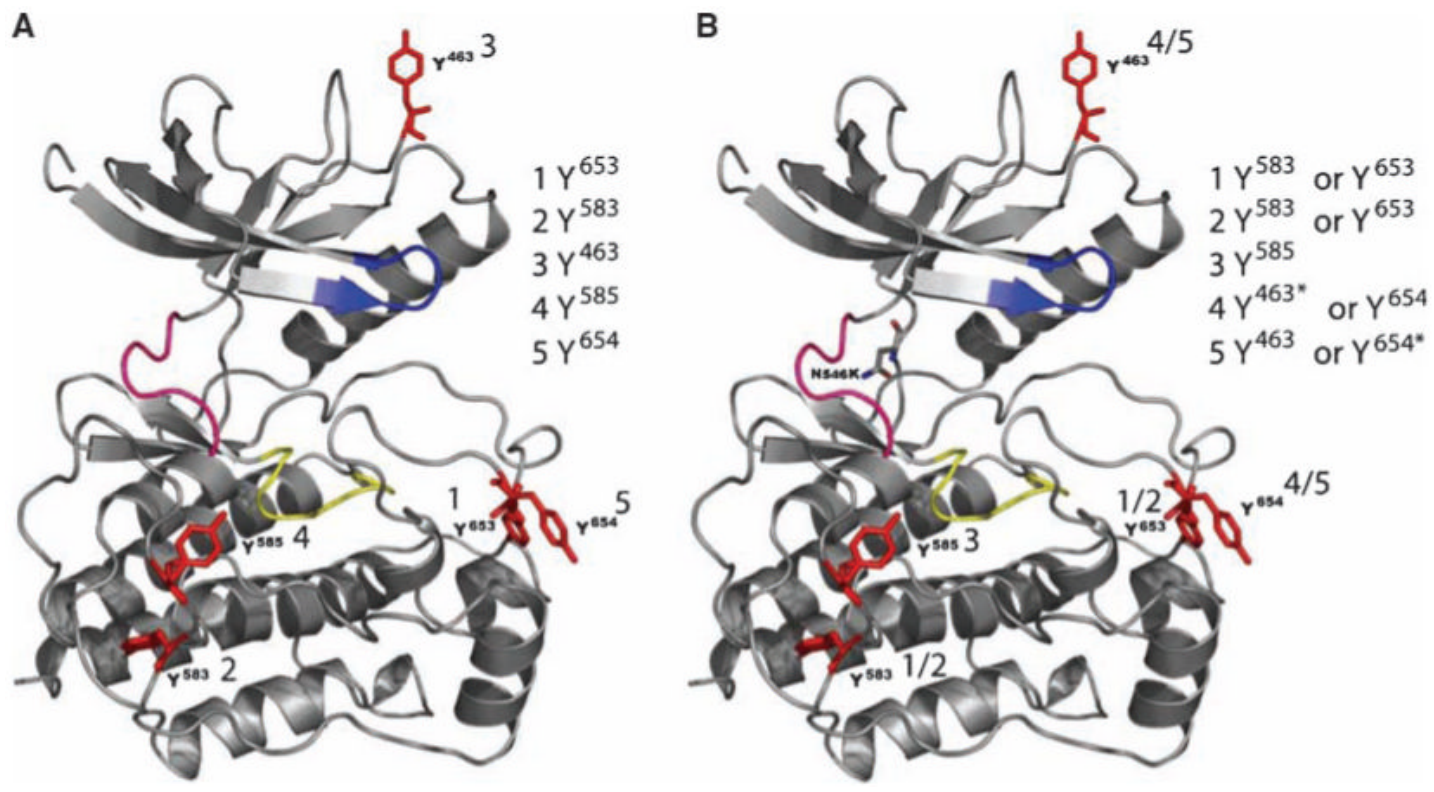

Fig. 4.

Molecular model of FGFR1 mutation implicated in glioblastoma, depicting order of autophosphorylation. The nucleotide binding pocket is shown in blue, the hinge region in magenta, and the catalytic cleft in yellow. The tyrosine phosphorylation sites are depicted and high-lighted in red. The observed order of autophosphorylation obtained by rapid chemical quench and subsequent LC/ESI-MS/MS is indicated. For the FGFR1 glioblastoma mutants, heterogeneous phosphorylation was observed at the fourth and fifth sites, but the intensity of the peptide peaks by LC/ESI-MS/MS suggests that the site indicated by a star was the preferred phosphorylation site. (A) FGFR1 kinase wild type (WT). (B) Glioblastoma-derived FGFR1_N546K mutation is found near the hinge region of FGFR1 kinase and is indicated on the structure. 
A

FGFR1_WT
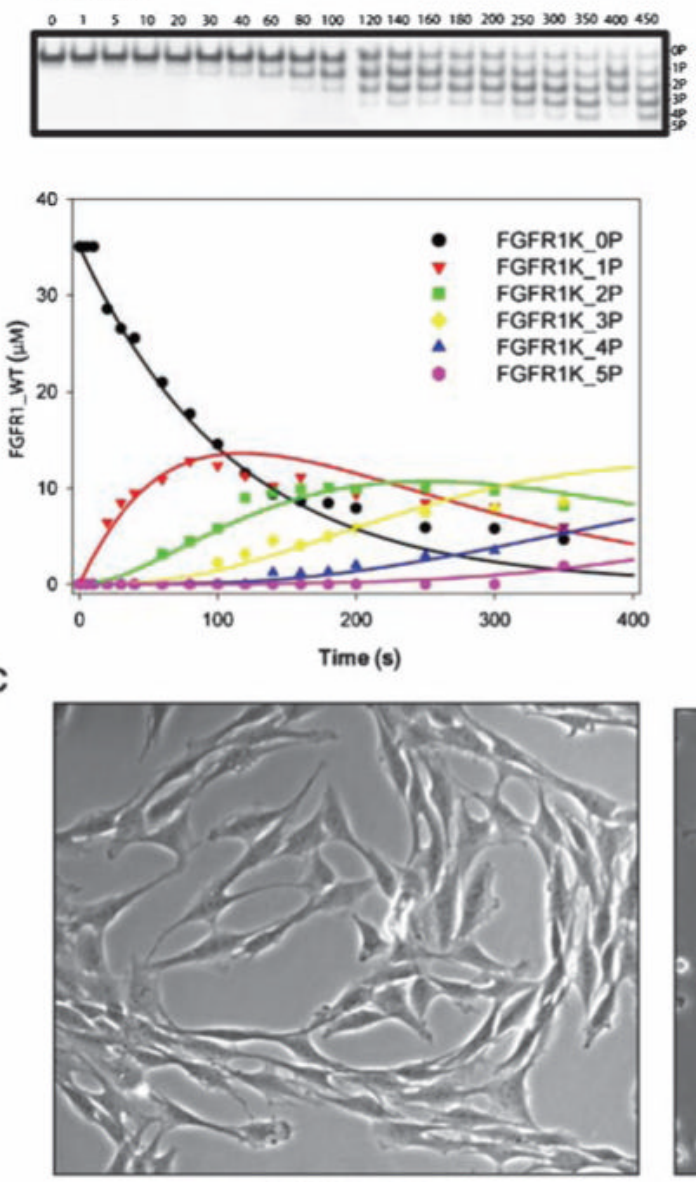

FGFR1_WT
B

FR1_NS46K
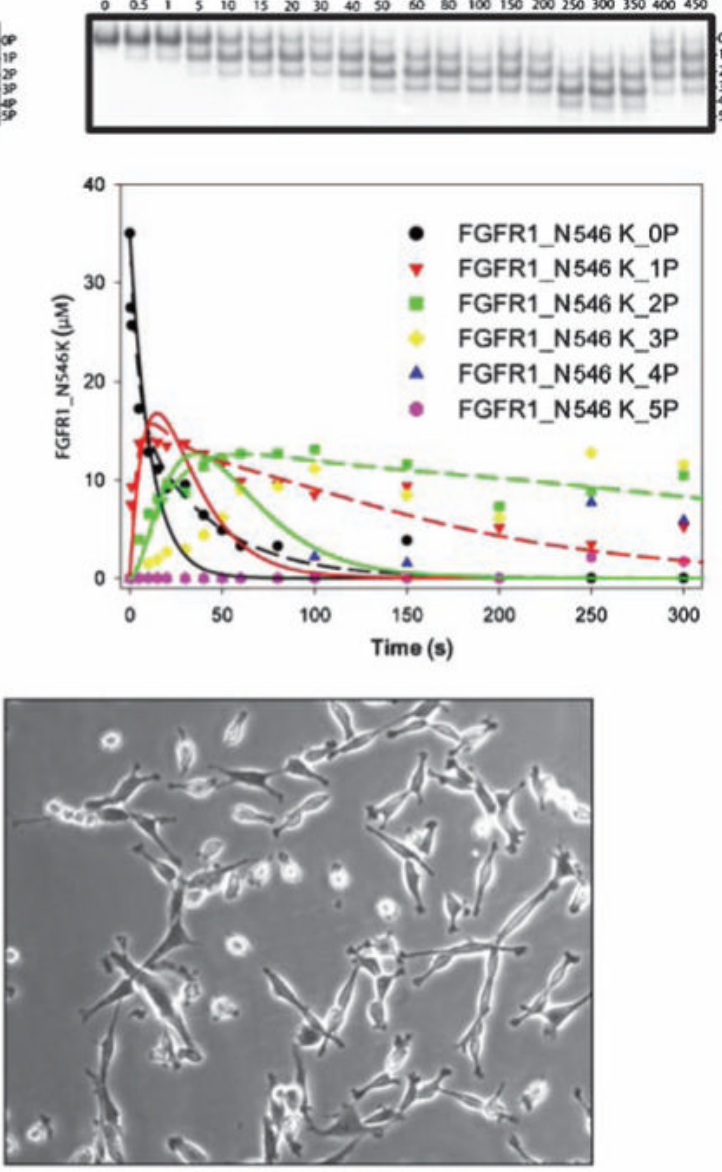

FGFR1_N546K

Fig. 5.

Effect of glioblastoma-derived N546K mutation on FGFR1 autophosphorylation and cell signaling. Wild-type FGFR1 (FGFR1_WT) and FGFR1 harboring an N546K point mutation $(35 \mu \mathrm{M})$ were reacted with $5 \mathrm{mM}$ ATP and $10 \mathrm{mM} \mathrm{MgCl}_{2}$ in a rapid chemical quench apparatus and quenched by addition of $83 \mathrm{mM}$ EDTA. The different phosphorylation states at each time point were separated by native PAGE. The kinetic parameters are summarized in table S1. (A) Native-PAGE and kinetic analysis of wild-type FGFR1 autophosphorylation. (B) Native PAGE and kinetic analysis of FGFR1K_N546K autophosphorylation. As illustrated by the solid line fit, the data did not fit well with the monophasic mechanism used to describe the kinetics of wildtype FGFR1. Rather, a biphasic mechanism (dashed line) was required to accommodate and best describe the phosphorylation kinetics of this mutant. (C) Rat-1 cells stably expressing either wild-type FGFR1 or a glioblastoma-derived FGFR1_N546K mutant. 